\title{
Correction for Perry, "A Decade of Development of Chromogenic Culture Media for Clinical Microbiology in an Era of Molecular Diagnostics"
}

\section{John D. Perry}

Microbiology Department, Freeman Hospital, Newcastle upon Tyne, UK

Volume 30, no. 2, p. 449-479, 2017, https://doi.org/10.1128/CMR.00097-16. Page 457, line 1: "a simple disk test for pyroglutamyl aminopeptidase" should read "a simple disk test for L-proline aminopeptidase."
Published 13 September 2017

Citation Perry JD. 2017. Correction for Perry, "A decade of development of chromogenic culture media for clinical microbiology in an era of molecular diagnostics." Clin Microbiol Rev 30:vii. https://doi.org/10.1128/CMR.00073-17.

(c) Crown copyright 2017. The government of Australia, Canada, or the UK ("the Crown") owns the copyright interests of authors who are government employees. The Crown Copyright is not transferable. 